BOJAN STANIVUKOVIĆ, Ph.D. ${ }^{1}$

E-mail: stanivukovic@yahoo.com

VALENTINA RADOJIČIĆ, Ph.D. ${ }^{1}$

E-mail: valentin@sf.bg.ac.rs

DEJAN MARKOVIĆ, Ph.D. ${ }^{1}$

E-mail: mdejan@sf.bg.ac.rs

MLADENKA BLAGOJEVIĆ, Ph.D. ${ }^{1}$

(Corresponding author)

E-mail: m.blagojevic@sf.bg.ac.rs

${ }^{1}$ University of Belgrade

Faculty of Transport and Traffic Engineering

Vojvode Stepe 305, Belgrade 11000, Serbia
Information and Communication Technology

Original Scientific Paper

Submitted: 13 Aug. 2017

Accepted: 10 July 2018

\title{
DEMAND FORECAST OF NFC MOBILE USERS - A CASE STUDY OF SERBIAN MARKET
}

\begin{abstract}
Near Field Communication (NFC) is a very short-range type of radio communication that is compatible with other contactless communication technologies. It provides enormous possibilities, particularly given that it does not require any particular communication infrastructure. NFC technology has found possible application in contactless cards and mobile phone devices as a communication infrastructure which provides a platform for the development of NFC-based business services. This paper proposes a novel approach to forecasting the number of new users of NFC mobile phones based on fuzzy logic and the Norton-Bass diffusion model. The proposed approach is demonstrated through the case study.
\end{abstract}

\section{KEYWORDS}

fuzzy logic; Near Field Communication; mobile users; forecast;

\section{INTRODUCTION}

\subsection{Motivation}

Mobile payment is a relatively new area of research. Although mobile payment systems provide flexibility and convenience, they still cannot compete with the traditional payment services [1]. Some authors argue that mobile payment adoption research is in its infancy $[2,3]$, even if the number of studies has increased in the last couple of years [4]. The technology supporting the mobile payment systems has evolved in the last few years, following the emergence and expansion of a full new range of mobile and smart devices, some of them already using technologies like Near Field Communication (NFC) [5].

NFC is a very short-range type of radio communication that enables contactless cards and NFC mobile devices to communicate, exchange data, and share resources, and it represents the technology of future which will introduce a completely new way of communication, business, trade, marketing, arts, health, social care, security, and the like. The implementation of NFC chips in all new mobile phone devices makes a platform for introducing a range of new services based on this technology.

The development history of NFC technology is associated with NFC contactless cards that have provided the first technological platform and user experience of this technology. The question is how do the NFC and its mobile application contribute to the development of market dynamics? On a global scale, as well as in small isolated markets, the basic assumptions are that the NFC technology migration from contactless cards to mobile phones will be gradual and will depend on two very important factors:

- The development of the NFC mobile phone market, i.e., the increase in the number of mobile phones with NFC chips and interest of end users to have such phones, and

- Awareness of users who may be interested in the transition to a new technology, driven by the benefits it offers them, particularly in terms of multi-functionality and security.

Reviewing the related literature, the only published articles concern the understanding of the determinants of customer adoption and intention to recommend mobile payment technology [5], adoption of NFC mobile payment system by the end user [1], mobile technology acceptance model - an investigation using mobile users to explore smartphone credit card [6], a neural networks approach for predicting the determinants of the NFC-enabled mobile credit card acceptance [7]. Although there has been a lot of coverage on consumer acceptance of mobile payments, there are few studies providing guidelines to interpret NFCbased mobile payment adoption [8]. Having reviewed the existing literature in terms of NFC technology 
adoption, we found only articles aimed at researching the willingness of consumers to accept m-payment and NFC technology. There are no papers dealing with consumers' willingness and intention to switch from one kind of NFC technology to another, i.e., from NFC contactless cards to NFC mobile phones, and that was the motivation for this paper.

\subsection{Research objective and questions}

The Serbian market is rather shallow, both in the area of card management business and in the mobile application management business. Even though there are pilot projects of NFC technology usage on the contactless card platform, the market expansion is quite slow. Among numerous small projects, two larger projects are emerging, and they are based on the contactless card platform: Intesa-MTS-Maestro-PayPass payment cards and BusPlus cards for public transportation services in Belgrade, Serbia. On the other hand, it has been established that the number of mobile phone subscribers is higher than the total number of inhabitants. According to RATEL (Regulatory Agency for Electronic Communications and Postal Services) data, the penetration of mobile phone subscribers in the year 2010 was $132.24 \%$, in the 2011 it amounted to $142.99 \%, 126.19 \%$ in $2012,128.09 \%$ in 2013 , and $130.76 \%$ in 2014 [9]. This substantial technical capital of the market raises the question regarding the dynamics and range of development of the NFC mobile phone market in Serbia. Based on the above assumptions, the research objective is providing a deeper understanding of the factors facilitating the current consumer's transition from one method of mobile payment to another, both based on NFC technology, and forecasting the NFC mobile users' demand on the Serbian market.

In order to achieve the research objective, there are some research questions which should be addressed, as follows:

- Today, customers are unlikely to switch to NFC mobile payment unless additional services add value and give them a reason to do so. Can we expect significant customer transition from NFC contactless cards to NFC mobile phones?

- Beside traditional forecast models, which model is the most appropriate to combine prediction theory and social factors for assessment of the number of users switching to NFC mobile phones?

This paper proposes a novel approach to forecasting the number of new users of NFC mobile phones based on fuzzy logic and diffusion theory.

The paper is organized as follows. Section 2 provides background knowledge that supports the reasoning behind our research. A description of the fuzzy logic approach is presented in Section 3. An estimation of the relevant parameters for NFC technology adoption is given as well. Section 4 provides a description of the forecasting procedure using the Norton-Bass diffusion model. Section 5 includes the obtained results and discussion. The forecasted results are evaluated in Section 6, followed by the conclusions at the end of the paper.

\section{RESEARCH BACKGROUND}

The NFC standard was established in 2003 and is defined in the standard ISO/IEC 18092. It is compatible with ISO/IEC 14443 and ISO/IEC 15693 and with Sony FeliCa contactless smart cards [10]. In that way, NFC can use the existing RFID (Radio Frequency Identification) infrastructure, eliminating the need for any specific technical conditions or its own infrastructure. A key advantage of NFC devices is that they can read RFID transponders and emulate them.

Apart from the above, the key NFC advantages for end users are [11]:

- Versatility: NFC is a protocol for communication between devices that can be used in the widest spectrum of human activity;

- Intuitiveness: NFC does not require more than a simple touch at the touch tag to set up interaction between devices;

- Set-up technology: NFC facilitates fast and simple setting up of wireless communication in other wireless technologies, such as RFID, Bluetooth, Wi-Fi, etc.;

- Open source based on: ISO, ECMA, and ETSI standards. The basic NFC standards are ISO 14443 Types A and B + FeliCa, which is the international standard for contactless smart cards working at $13.56 \mathrm{MHz}$, and the international standard ISO 18092 defining the regime for NFC interface and communication protocol [12];

- Self-secure technology: the NFC protocol is a shortrange protocol (from touch up to 10 centimeters) and represents a secure and self-preserving form of communication;

- Security: NFC has a built-in support possibility for various forms of secure protocols and secure application development;

- Compatibility: NFC is compatible with all existing contactless communication technologies, including contactless card technologies.

The NFC technology offers a range of various possibilities in creating new services when contactless smart cards are concerned, but it provides the biggest advantage to mobile applications within m-business. NFC mobile phones are used for interaction with posters, magazines, and even with products in shops. With such interactions, certain requirements are initiated or specific related information is requested in real time [13]. In addition, the NFC technology enables mobile phones to be transformed into electronic wallets for payment of a wide spectrum of products and services, 
as well as the integration of debit/credit cards for payment of goods and services at point-of-sale devices [14]. From an end user point of view, the introduction of NFC interfaces should bring improved convenience and functionality and replace plastic cards (for payment, ticketing, transport, etc.). An example of the improved functionality is displaying real-time information about mobile NFC services using applications in mobile handsets, which is something that is not possible with plastic cards as these do not possess display capabilities [15].

There are two directions of mass NFC technology use: smart contactless cards and mobile phone devices. Smart cards present a simple solution that will lead to a massive usage of this technology, but due to technical and technological limits they will very soon be replaced with mobile phone devices which will be the basic standard for personal communication, identification, and business interaction in the sphere of electronic business [16]. The results of the study conducted in the paper [8] revealed that intention to adopt NFC mobile payments is affected the most by product-related factors, personal-related factors, and attractiveness of alternatives.

There are three recognized phases in the development of the NFC technology which will be a driving force of e-smart business development [17]:

1) Contactless card phase - we are in this phase at the moment, and it will enable the numerous advantages of this new technology to be assessed.

2) The phase of adding the NFC chip in mobile phones - as a hardware/software addition which is optionally built into phones. After the pilot projects, this phase has already come into practice, and it represents the adaptation phase for both service users and the overall market of service providers.

3) Integration phase of the NFC chip into mobile phones - as the last phase of the NFC technology development which is bound to change the entire approach in m-commerce and open a way to rendering integral services within e-smart business.

In expert circles, 2011 has been declared as the year when the mass use of the NFC technology started and a new m-commerce market was created. As of that year, almost all mobile phone manufacturers have been implementing NFC chips in their mobile devices.

The biggest danger of introducing NFC technology is consumers' acceptance of this new service. That fear is justified since it is reasonable to expect that the initial phase of accepting the NFC technology will take some time. Even though NFC mobile payments are invested into by collaboration between mobile network operators (MNOs) and banks, there is still a poor understanding of consumer motivation for NFC mobile payment use. In addition, the adoption of NFC mobile payment is still not widespread despite its documented potential [8].
Future users will obviously be compelled to use this new technology and its significant advantages and possibilities [18]. The initial introductory phase has to be properly promoted in order to dispel any fear of misuse and encroachments on clients' privacy due to use of data concerning them and their reactions, buying behavior, and habits. The issue of encroaching on client privacy may actually be the biggest obstacle in fast implementation of new services on the NFC platform [19]. Privacy and safety are central issues in clients' perception of the use of NFC-based services. Apart from promotion activities, user education will be necessary, and that should provide a full integration of clients in the m-business model.

\subsection{Fuzzy logic}

There is a need to investigate the antecedents of NFC mobile payment adoption in the context of NFC contactless cards and NFC mobile phones in order to provide more insight into the intention of consumers to switch to NFC mobile phones. There is a paucity in the research of NFC-enabled mobile phones, and limited studies $[20,21]$ have been conducted so far. Although there are many studies on technological innovations, we found none concerning the substitution of one NFC technology by another. Hence, this study will serve to narrow the research gap by presenting a possible way to predict the number of NFC mobile phone users, using diffusion theory and fuzzy logic.

Fuzzy logic was first proposed by Lotfi A. Zadeh, from the University of California at Berkeley [22]. He elaborated his ideas in a paper from 1973 that introduced the concept of "linguistic variables", which in this article equates to a variable defined as a fuzzy set. The papers [23] and [24] presented the first application of the fuzzy set theory in the control of a dynamic process. In recent literature, quite a few papers that use fuzzy logic for forecasting have been published. The paper [25] describes an application of evolutionary algorithms to predictive modeling of user behavior in a business environment. Predictive models are represented as fuzzy rule bases, which allow for intuitive human interpretability of the results obtained, while providing satisfactory accuracy. The authors of the paper [26] developed an expert system to forecast demand by neuro-fuzzy techniques. Finally, an excellent literature survey of fuzzy logic applications on the prediction process can be found in [27]. In this paper, we use fuzzy logic to obtain the relevant parameters of the Bass model in order to forecast NFC adoption.

\subsection{Diffusion theory}

Diffusion theory is often used to forecast the demand of a new service/technology. Marketing managers need a basic understanding of the principles of technology change and adoption [28]. These actions 
can help to forecast market share. The most important model in this stream of research is the basic Bass model [29]. The Bass diffusion model describes the empirical adoption curve by using two important factors: innovation and imitation parameters. The diffusion of an innovation has been defined as the process by which that innovation is communicated through certain channels over time among the members of a social system [30]. In practice, new products or services are often substituted with more advanced products and services. In terms of practical impact, the main application areas of innovation diffusion modeling and forecasting are the introduction of consumer durables and telecommunications [31]. New product growth across technology generations occupies a growing interest among marketing scholars [32-36]. New generation technologies give users better products that they value more. When new technologies become available, it provides a potential for adopters of earlier technologies to substitute those earlier technologies with new ones. In the paper [37], the authors modified the Bass model to apply it to successive generations of technology. In this paper, we focus on the Bass diffusion model and its extension [37], which includes both substitution and competition.

\section{ESTIMATION OF RELEVANT PARAMETERS}

Fuzzy logic provides a formal methodology for representing and implementing a human's heuristic knowledge on how to control or predict some phenomena. It can be used to model systems that are hard to define precisely. As a methodology, fuzzy logic incorporates imprecision and subjectivity into the model formulation and solution process. Fuzzy logic represents an attractive tool to aid research in forecasting when the dynamics of the environment limit the specification of model objectives, constraints, and precise measurement of model parameters.

Fuzzy logic is unique in its ability to utilize both qualitative and quantitative information. Qualitative information is gathered not only from the expert operator strategy, but also from the common knowledge.

The fuzzy logic process is very simple conceptually. It consists of three stages: input stage, processing stage, and output stage (see Figure 1).
Fuzziness is best characterized by its membership function. Membership functions were first introduced in 1965 by Lofti A. Zadeh. Membership functions characterize fuzziness (i.e., all the information in a fuzzy set), whether the elements in fuzzy sets are discrete or continuous [21]. The most common shape of membership functions is triangular, although trapezoidal and bell curves are also used, but the shape is generally less important than the number of curves and their placement. A fuzzy rule is defined as a conditional statement in the form: IF $x$ is A, THEN $y$ is $B$, where $x$ and $y$ are linguistic variables. $A$ and $B$ are linguistic values determined by fuzzy sets on the universe of discourse $X$ and $Y$, respectively.

The processing stage is based on a collection of logic rules in the form of IF-THEN statements, where the IF part is called the antecedent, and the THEN part is called the consequent. A typical fuzzy logic process has dozens of rules.

There are several different ways to define the result of a rule, but the one used in this paper is the most common Mamdani max-min inference method, in which the output membership function is given the truth-value generated by the premise [38] (see Figure 2).

The results of all the rules that have fired are defuzzified to a crisp value by one of several methods, but we used the very popular centroid method, in which the center of mass of the result provides the crisp value (see Figure 2).

Here, we propose a new approach for forecasting the percentage of users who will decide to use a new kind of NFC technology, named mobile NFC, and it is based on fuzzy logic. Fuzzy logic is applied in order to model unprecise and linguistic variables. As can be seen from Figure 3 , the percentage of users who will decide to use new NFC mobile technology depends on their preferences, satisfaction, and willingness. All these merits are impossible to express by crisp numerical values. The design of a prediction model based on fuzzy logic requires compliance to precise methodology. In particular, the choice of input variables, membership-type functions for these variables, the vocabulary used, and the intervals to be applied in the fuzzification phase very significant. It is also important to clarify the rules to be applied and membership-type function for the output variable.

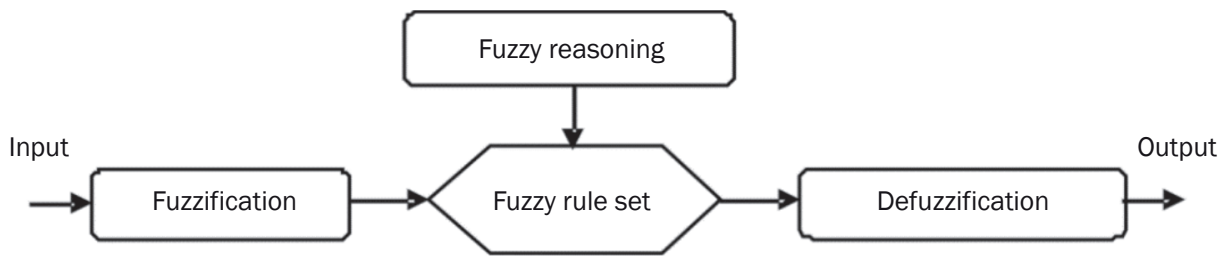

Figure 1 - Fuzzy logic process 


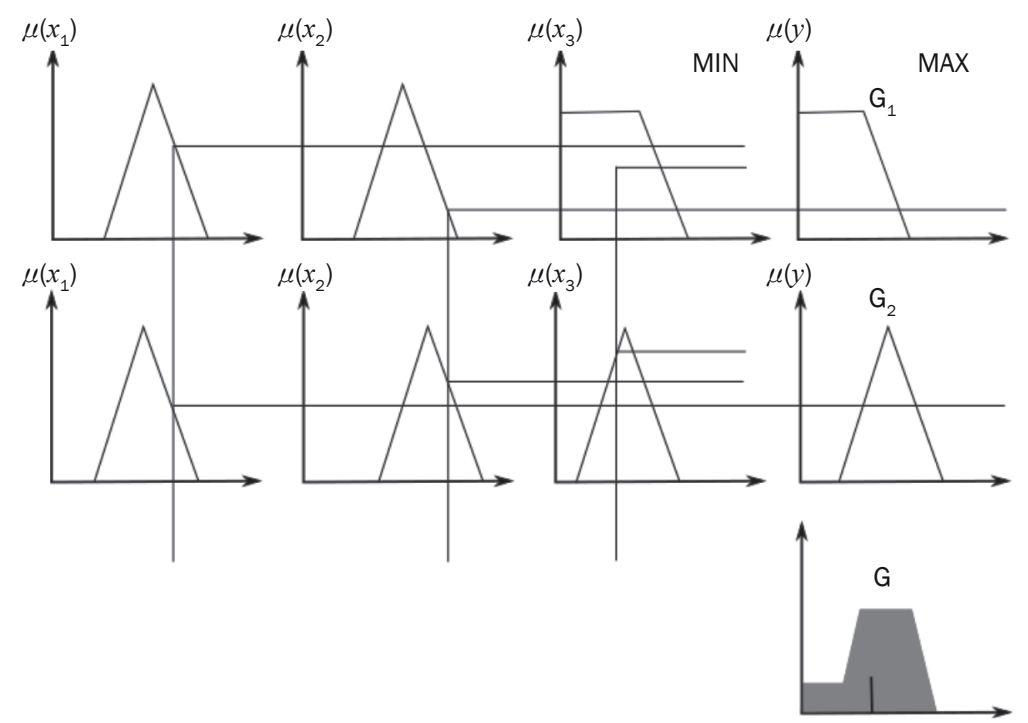

Figure 2 - Mamdani max-min inference method [38]

\subsection{Data gathering}

For the purpose of NFC technology prediction, a survey of the Serbian market was carried out. The survey is based on researching a representative sample of 1,000 respondents with the following age, gender, and educational structure:

- $30 \%$ of respondents up to the age of $30,30 \%$ of respondents between the ages of 30 and 40, 30\% of respondents between the ages of 40 and 50 , and $10 \%$ of respondents over the age of 50 (such division is a consequence of striving to poll respondents of working age, namely potential users of contemporary communication technologies);

- The gender structure was as follows: 51\% female respondents, and $49 \%$ male respondents (division was made according to official statistical data in Serbia) who were evenly assigned to age groups;

- The educational structure was as follows: $50 \%$ with secondary education and 50\% with higher education - division into these two categories is a product of the intention to have more objective respondents' answers, where the corrective factor shall not be the level of education.

The use of NFC technology via the contactless card platform on the Serbian market is very small. Therefore, after the sample selection we explained the NFC technology with all parameters and possibilities of usage to respondents. The model and the NFC technology used on the contactless card and mobile phone platforms were presented to respondents through the following usage parameters:

- Knowledge and technology recognition - estimation of new technology recognition;

- Loyalty - determination of belonging to user groups from the recognition aspect;
- Innovativeness - estimation of the number of innovators as new technology development starters;

- Safety - different aspects of general safety and safety by levels of usage;

- Simplicity - estimation of user-friendly approach to technologies through usage and maintenance;

- Usage speed - assessment of simplicity through usage speed;

- Flexibility - estimation of technology adjustment to specific requirements;

- Accessibility - determining the technology accessibility from technical and user aspects;

- Difference - assessment of differences in order to define specificities of technologies;

- Reliability - estimation of system reliability in critical situations;

- Prestige - assessment of user status through use of these technologies;

- Risk - assessment of faults in using technologies from the aspect of functional safety;

- Multi-functionality - evaluation of benefits of these two technologies from the aspect of functionality;

- Technology limitation - aspects of technical and user functional limitation;

- Marketing applicability - estimation of the possibility for application of promotions, issuance of coupons and vouchers, initiation of promotion actions, information placement, and the like;

- CRM - estimation of user satisfaction through customer relationship management;

- Notification - assessment of notification possibilities for users, service providers, and third parties;

- Compatibility - comparability and functionality evaluation against similar or complementary technologies; 
- Interoperability - evaluation of functionality with other software and hardware - internet applicability and the like;

- User costs - determination of costs of using certain technologies from the aspect of users;

- Migration cost - determination of costs that occur during the transition process from one to another technology from the aspects of users and service providers;

- Operator cost - determination of the technology exploitation costs from the aspect of the banks, providers, and telecommunication companies.

Using the Delphi method [39] or iterative procedure of congregating expert opinion through a series of questionnaires, the main goal was to determine those parameters which are the most relevant for the prediction of the number of users to transit to the NFC mobile technology. In this way, nine parameters were adopted as variables for the fuzzy logic model described in the next subsection.

\subsection{Choice of input variables}

Modeling a prediction system based on fuzzy logic consists of identifying input values, membership-type function, and linguistic variables for each input.

The model analyzed in this paper consists of two parts. The first part represents three fuzzy logic systems. The first logic system consists of the inputs of risk, reliability, and compatibility. The second logic system consists of the inputs of multi-functionality, marketing applicability, and limitations of existing technology (like contact credit cards, contactless credit cards, etc.). The third logic system consists of the inputs of cost of migration, innovation, and prestige). These three fuzzy logic systems determine the values of the output variables that are at the same time the input variables to the second part. The second part of the model is also a fuzzy logic system, which is used to obtain preference for user transition to the new mobile NFC technology (see Figure 3). The output value (preference for user transition to the new mobile NFC technology) depends on the relation between the security of existing (contactless NFC) technology, satisfaction with existing technology, and the willingness to accept new (mobile NFC) technology.

In terms of fuzzy logic, each of these input parameters are individually analyzed and reformulated. Security of existing contactless technology is the output value of the fuzzy logic system in which the input parameters are:

- Risk - user assessment of the risk of transition to new technology based on an assessment of current and projected security risk of new technology.

- Reliability - estimation of reliability of existing technology from the point of user perception on safety of use.

- Compatibility - evaluation of existing technology's compatibility with all known systems of protection, especially in relation to new technology and its possibilities.

In addition, satisfaction with existing, contactless technology depends on:

- Multi-functionality - evaluation of existing technology's multi-functionality with focus on its usage in other areas (transport, trade, health, e-government, marketing, entertainment, etc.).

- Marketing applicability - estimation of existing technology's marketing application in relation to new technology.

- Limitations of existing technology - judgment of limitations of existing technology which can produce an attitude and decision about transition to the new NFC technology, from user point of view.

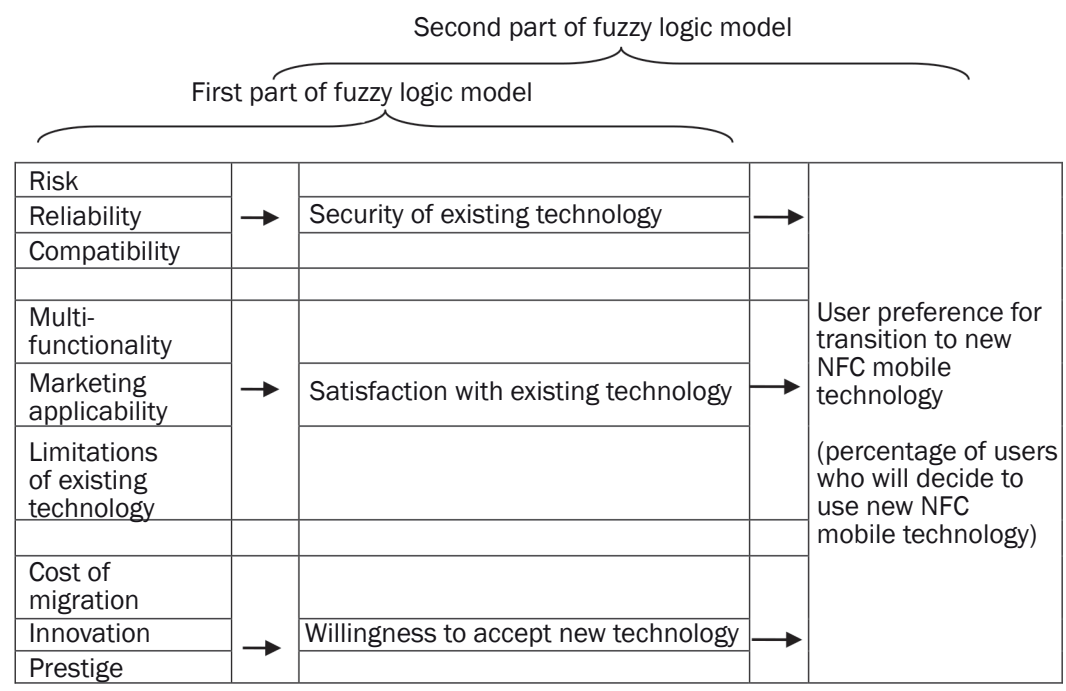

Figure 3 - Fuzzy logic model for forecasting purposes 
Finally, willingness to accept new, mobile NFC technology is in relation with three input parameters:

- Cost of migration - user estimation of relative costs that occur during transition process.

- Innovation - user assessment of their own innovative attitude.

- Prestige - assessment of new technology prestige.

\subsection{Input membership function}

The most important step in the formation stage of the fuzzy logical system is to properly define the fuzzy rule set. The fuzzy rule set was formed based on "ifthen" rules. One possible rule would state: IF the security of existing technology is low, and IF the satisfaction with existing technology is small, and IF the willingness to accept new technology is high, THEN preference for transition to the new mobile NFC technology is very high.

For each of the mentioned input variables that characterize the three fuzzy logic models, we defined the appropriate intervals. All input variables were separated into three classes: small, medium, and high, and they are measured in percentages, which are scaled in the range from 0 to 1 (Table 1 ).

We formed membership functions for each of the input variables, and we used the triangular shape (for the forming and testing phase of the logical model we used the Matlab r2008a software). The following tables show membership functions for each of the input variables. The authors determined the values of the membership functions based on long-standing experience and expert opinions. This is a major characteristic of fuzzy modeling. All is based on subjective expert opinion.
The output variables of the previously described fuzzy models are at the same time the input variables of the next fuzzy model, which determines preference for user transition to the new mobile NFC technology. These variables are explained in Table 2.

Finally, the output variable is defined as the user preference for transition to the new mobile NFC technology (percentage of users who will decide to use new NFC technology), and it is divided into five intervals: very low, low, average, high, and very high. To define the output variable membership functions, we used triangular fuzzy numbers.

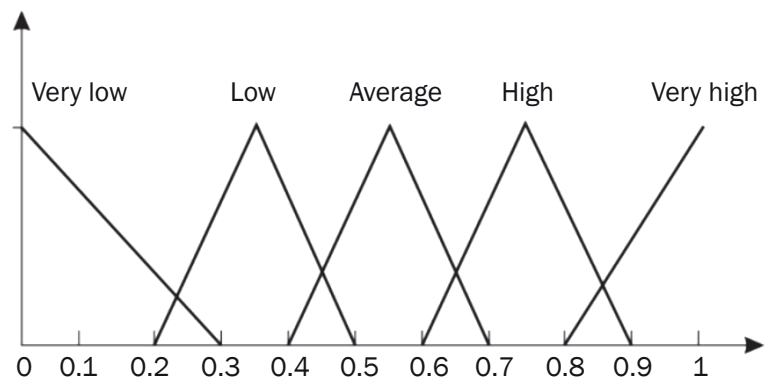

Figure 4 - Membership function

Figure 4 shows the membership functions of the user preference for transition to the new mobile NFC technology. The intersection and threshold subsets are defined based on experimental study and analysis.

\section{FORECASTING OF ADOPTION OR SUBSTITUTION}

The mathematical structure of the Bass model is derived from a hazard function corresponding to the conditional probability that adoption will occur at time

Table 1 - Input variables

\begin{tabular}{|c|c|c|c|}
\hline Input variables & Small & Medium & High \\
\hline Risk & from 0 to 0.5 & from 0.3 to 0.7 & from 0.5 to 1 \\
\hline Reliability & from 0 to 0.4 & from 0.3 to 0.7 & from 0.6 to 1 \\
\hline Compatibility & from 0 to 0.3 & from 0.1 to 0.9 & from 0.7 to 1 \\
\hline Multi-functionality & from 0 to 0.5 & from 0.4 to 0.6 & from 0.5 to 1 \\
\hline Marketing applicability & from 0 to 0.4 & from 0.3 to 0.7 & from 0.6 to 1 \\
\hline Limitations of existing technology & from 0 to 0.3 & from 0.2 to 0.6 & from 0.4 to 1 \\
\hline Cost of migration & from 0 to 0.5 & from 0.3 to 0.7 & from 0.5 to 1 \\
\hline Innovation & from 0 to 0.4 & from 0.3 to 0.7 & from 0.6 to 1 \\
\hline Prestige & from 0 to 0.4 & from 0.3 to 0.7 & from 0.5 to 1 \\
\hline
\end{tabular}

Table 2 - Values used for membership function definition as input variables

\begin{tabular}{||l|c|c|c||}
\hline & Security of existing technology & Satisfaction with existing technology & Willingness to accept new technology \\
\hline \hline Low & from 0 to 0.5 & from 0 to 0.5 & from 0 to 0.45 \\
\hline Medium & from 0.3 to 0.7 & from 0.4 to 0.8 & from 0.2 to 0.8 \\
\hline High & from 0.5 to 1 & from 0.7 to 1 & from 0.55 to 1 \\
\hline
\end{tabular}


$t$ given that it has not occurred yet [40]. If $f(t)$ is the density function of time to adoption, and $F(t)$ is the cumulative fraction of adopters at time $t$, the basic hazard function underlying the Bass model is [29]:

$$
\frac{f(t)}{1-F(t)}=p+q \cdot F(t)
$$

From the differential Equation 1 with the initial condition $F(0)=0$, the solution of purchase cumulative distribution function $F(t)$, cumulative demand forecast, i.e., forecasted number of users $N(t)$, and non-cumulative adoptions $S(t)$, can be found, as follows [41]:

$$
\begin{aligned}
& N(t)=m F(t)=m \frac{1-e^{-(p+q) t}}{1+\left(\frac{q}{p} e^{-(p+q) t}\right)} \\
& S(t)=m f(t)=p m+(q-p) N(t)-\frac{q}{m} N^{2}(t)
\end{aligned}
$$

This model has three key parameters: the parameter of innovation or external influence $(p)$, the parameter of imitation or internal influence $(q)$, and the market potential $(m)$. Parameter $q$ reflects the influence of those users who have already adopted the new technology (i.e., word-of-mouth communication from previous adopters), while $p$ captures the influence that is independent from the number of adopters (i.e., external communication) [40]. These three parameters could be estimated using historical sales data. The size of the market potential $m$ is the most critical element in forecasting matters.

Norton and Bass [34] extended the basic Bass model to incorporate the idea of competing generations of technology. Key simplifications include only permitting a shift from the first to the second generation. The diffusion parameters can be different for each generation. It is assumed that each generation has its own market potential, i.e., potential adopters of earlier generations can shift to newer generations through substitution. This paper assumes two technology generations. The first generation of the technology is introduced at $t=0$, and the second generation is introduced at $t=\tau>t$. The mathematical formulation of the Norton-Bass model for the two technology generations is given by the equations [34]:

$$
\begin{aligned}
& N_{1}(t)=m_{1} F_{1}(t)\left[1-F_{2}(t-\tau)\right] \\
& \text { for } t<\tau F_{2}(t-\tau)=0 \\
& N_{2}(t)=\left[m_{2}+m_{1} F_{1}(t)\right] F_{2}(t-\tau) \\
& \text { for } t>\tau F_{2}(t-\tau) \neq 0
\end{aligned}
$$

where $N_{1}(t)$ and $N_{2}(t)$ represent the cumulative adoptions in the first and second technology generations, respectively; $m_{1}$ and $m_{2}$ refer to the market potential of the first and second generations, respectively; $\tau$ is the time at which the second generation is introduced. Generally, the solution of the cumulative distribution function $F_{i}(t)$, for each technology generation $I$, is given by Equation 6 [34]:

$$
F_{i}(t)=\frac{1-e^{-\left(p_{i}+q_{i}\right) t}}{1+\left(\frac{q_{i}}{p_{i}} e^{-\left(p_{i}+q_{i}\right) t}\right)}, \text { for } i=1,2
$$

where $p_{i}$ represents the parameter of innovation of the $i$-th technology generation, and $q_{i}$ refers to the parameter of imitation of the $i$-th technology generation.

The regression parameters $(a, b$ and $c$ ) of the Bass model are determined by forming the following system of equations [41]:

$$
\begin{aligned}
& \sum_{t=1}^{n} s_{t}=a n+b \sum_{t=1}^{n} N_{t-1}+c \sum_{t=1}^{n} N_{t-1}^{2} \\
& \sum_{t=1}^{n} s_{t} N_{t-1}=a \sum_{t=1}^{n} N_{t-1}+b \sum_{t=1}^{n} N_{t-1}^{2}+c \sum_{t=1}^{n} N_{t-1}^{3} \\
& \sum_{t=1}^{n} s_{t} N_{t-1}^{2}=a \sum_{t=1}^{n} N_{t-1}^{2}+b \sum_{t=1}^{n} N_{t-1}^{3}+c \sum_{t=1}^{n} N_{t-1}^{4}
\end{aligned}
$$

The estimation of the Bass diffusion parameters was done by linear regression [41] based on the historical sales data for contactless cards [9]. The results are presented in Table 3.

Table 3 - The values necessary to determine the regression parameters

\begin{tabular}{|c|l|l|l|l|l|l|l||}
\hline$t$ & \multicolumn{1}{|c|}{$s_{t}$} & \multicolumn{1}{|c|}{$N_{t-1}$} & \multicolumn{1}{|c|}{$N_{t-1}^{2}$} & \multicolumn{1}{|c|}{$N_{t-1}^{3}$} & \multicolumn{1}{|c|}{$N_{t-1}^{4}$} & \multicolumn{1}{c|}{$s_{t} N_{t-1}$} & \multicolumn{1}{c|}{$s_{t} N_{t-1}^{2}$} \\
\hline \hline 1 & 0.05 & 0 & 0 & 0 & 0 & 0 & 0 \\
\hline 2 & 0.078 & 0.05 & 0.0025 & 0.000125 & 0.00000625 & 0.0039 & 0.000195 \\
\hline 3 & 0.115 & 0.128 & 0.016384 & 0.002097152 & 0.000268435 & 0.01472 & 0.00188416 \\
\hline 4 & 0.133 & 0.243 & 0.059049 & 0.014348907 & 0.003486784 & 0.032319 & 0.007853517 \\
\hline 5 & 0.154 & 0.376 & 0.141376 & 0.053157376 & 0.019987173 & 0.057904 & 0.021771904 \\
\hline 6 & 0.161 & 0.53 & 0.2809 & 0.148877 & 0.07890481 & 0.08533 & 0.0452249 \\
\hline 7 & 0.2362 & 0.691 & 0.477481 & 0.329939371 & 0.227988105 & 0.1632142 & 0.112781012 \\
\hline 8 & 0.2354 & 0.9272 & 0.8596998 & 0.797113692 & 0.739083815 & 0.21826288 & 0.202373342 \\
\hline 9 & 0.2391 & 1.1626 & 1.3516388 & 1.571415222 & 1.826927338 & 0.27797766 & 0.323176828 \\
\hline 10 & 0.2409 & 1.4017 & 1.9647629 & 2.754008143 & 3.860293214 & 0.33766953 & 0.47331138 \\
\hline$\Sigma$ & 1.6426 & 5.5095 & 5.15379 & 5.671082 & 6.7569459 & 1.19129727 & 1.188572043 \\
\hline
\end{tabular}


The obtained regression parameters based on Equation 7 are: $a=0.061297986, b=0.307457943$, $c=-0.1288992$. The Bass model parameters $\left(p_{1}, q_{1}\right.$, and $m_{1}$ ) are calculated by the expressions [42]:

$p_{1}=\frac{-b+\sqrt{b^{2}-4 a c}}{2}$

$q_{1}=\frac{b+\sqrt{b^{2}-4 a c}}{2}$

$m_{1}=\frac{-b-\sqrt{b^{2}-4 a c}}{2}$

According to the above equations, we calculated that $p_{1}=0.023848781, q_{1}=0.331306724$, and $m_{1}=2.570277578$.

In order to forecast the total number of NFC mobile phone users, it is necessary to estimate the required Bass diffusion parameters values. To estimate the Bass innovation parameter, $p_{2}$, we used the analogy with a similar service, such us the previous technology, the contactless card. Because of that, it is considered that users will accept the new technology in the same way. This is followed by the assumption that $p_{1}=p_{2}=0.0238$. The Bass imitation parameter, $q_{2}$, obtained by the fuzzy logic approach, reflects the influence of those users who will adopt the new NFC technology during the time (i.e., word-of-mouth communication from previous adopters). As a result of this approach, the innovation parameter $q_{2}=0.84$ is obtained.

The market potential for NFC mobile phones is based on the projection for the Serbian smart phone market, according to [9], and it is $m_{2}=1.103$. The market potential for NFC mobile phone technology should increase after the new technology is introduced due to the greater possibilities of the new technology, marketing actions like advertising and promotional efforts, wider distribution, and reactions that follow the new technology.

\section{RESULTS AND DISCUSSION}

After fuzzy rules are formed, it is possible to determine the necessary percentage of users that will make the transition to the new mobile NFC technology. Thus, we formed 108 fuzzy rules in total. To obtain the best possible results, output and input membership functions were tailored. In addition, it is important to note that it was necessary to revise some rules in order to achieve satisfactory results. According to these results, $84 \%$ of users who participated in the questionnaire will migrate to the new mobile NFC technology. The rest of the surveyed users, $16 \%$ of them, will continue to use NFC contactless technology in the future.

The conducted survey clearly shows the possibility of predicting the phase of NFC contactless cards and establishing additional services on the NFC mobile phone platform. This radical step forward can also be explained by the fact that, without any additional marketing activities (actions) and introductions of new m-services, smart phone usage proportion in the total number of mobile phones in Serbia in the year 2015 increased from 15\% to 33\% [9].

Based on the statistical data, we performed the forecast for NFC cordless technology until the end of the year 2024. Building upon the Norton-Bass diffusion model, we proposed an innovative approach, which encompasses a fuzzy logic model for estimation of the imitation parameter. Based on such approach, we performed the forecast of the NFC mobile phone demand on the Serbian market until the end of the year 2024. The obtained results for the cumulative number of users of the two competing technologies are shown in Figure 5.

The obtained results are:

- The implementation of the NFC mobile technology started in 2012 and will reach the level of NFC contactless card in 2018;

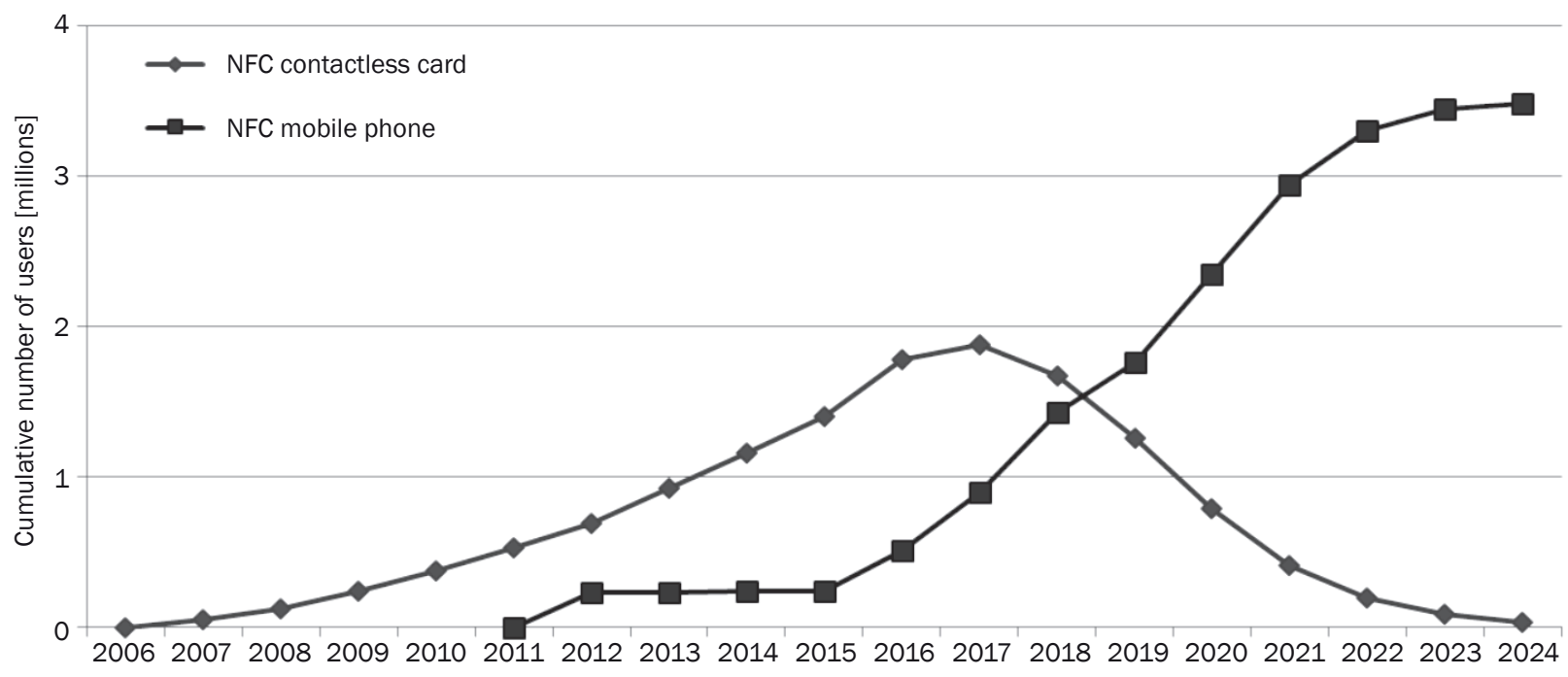

Figure 5 - Forecasted cumulative number of NFC products on the Serbian market until 2024 
- After 2018, the NFC contactless card technology will start to decrease. At the same time, the number of NFC mobile technology users will be growing, and in 2024 it will amount to 3.4 million users.

From the development economy and efficiency aspect, it must be taken into account that the development of a new NFC business service in Serbia on the NFC mobile phone platform would also cause enormous savings, particularly in the costs of replacing the contactless card technology with NFC-enabled mobile phones, as well as cost savings and increased efficiency by using the multi-functionality option, in particular on the NFC mobile phone platform.

Apart from the positive survey results shown in this paper, it must be taken into account that there are corrective factors that may influence the total market potential. First of all, the survey covered a sample of actively working and well-educated population, because of their easier perception of a new technology which may be abstract to average users. Therefore, it should be taken into account that this can be a corrective factor in the survey, given the official statistic data showing that in the total population corpus there is a substantial number of people with lower education and older people. However, that can also be taken as a realistic projection, since the target group of the NFC technology development will certainly be the segment of actively working and educated population. Apart from these corrections, the subject of the next study can also be a projection of the dynamics of introducing these systems in Serbia. This would contribute to perceiving a real picture of introducing the NFC technology on the mobile phone platform in Serbia.

\section{EVALUATION OF FORECASTED RESULTS}

In order to evaluate the precision of the obtained results, we performed the MAE (Mean Absolute Error), MAPE (Mean Absolute Percentage Error), and Durbin-Watson tests. Two standard error measures, MAPE and MAE, are employed to quantify the deviation in the data units. The lower the value of MAE or MAPE, the better fit of the model is achieved.

MAE calculates the mean absolute error function for the forecast and the eventual outcomes [43]. MAPE calculates the mean absolute percentage error (deviation) function [44]. MAE and MAPE tests are calculated by Equations $9 a$ and $9 b$.

$M A E=\frac{\sum_{i=1}^{n}\left|y_{i}-\hat{y}_{i}\right|}{n}$

$M A P E=\frac{100}{n} \cdot \sum_{i=1}^{n}\left|\frac{y_{i}-\hat{y}_{i}}{y_{i}}\right|$
The values obtained by MAPE can be evaluated by using the scale of judgment of forecast accuracy, as shown in Table 4.

Table 4 - A scale of judgment of forecast accuracy

\begin{tabular}{|l|c|}
\hline \multicolumn{1}{|c|}{ MAPE } & Judgment of Forecast Accuracy \\
\hline \hline Lower than $10 \%$ & Highly Accurate \\
\hline 11 to $20 \%$ & Good Forecast \\
\hline 21 to $50 \%$ & Reasonable Forecast \\
\hline $51 \%$ or higher & Inaccurate Forecast \\
\hline
\end{tabular}

The Durbin-Watson test should be used to check for systematic errors [45]. The test assumes calculating the value

$D W=2-\frac{2 w}{v}$

where parameters $w$ and $v$ are the following:

$w=\sum_{i=1}^{n-1}\left(y_{i}-\hat{y}_{i}\right)\left(y_{i+1}-\hat{y}_{i+1}\right)$ and $v=\sum_{i=1}^{n}\left(y_{i}-\hat{y}_{i}\right)^{2}$

The Durbin-Watson (DW) statistic lies in the range $0-4$. A value of nearly 2 indicates that there is no first-order autocorrelation. An acceptable range is 1.5-2.5. If the DW statistic gives an unsatisfactory test result, suitable adjustments must be made to the data and the analysis should be repeated. The forecasting results evaluations are given in Table 5 .

Table 5 - Statistical indicators of results precision

\begin{tabular}{|l|c||}
\hline \multicolumn{1}{|c|}{ Test } & Norton-Bass model \\
\hline \hline MAE & 0.78 \\
\hline MAPE [\%] & 9.03 \\
\hline Durbin-Watson & 0.38 \\
\hline Number of observation & 10 \\
\hline
\end{tabular}

The Norton-Bass model has a highly accurate forecast (MAPE) and low forecasting error (MAE). The Durbin-Watson test result is lower than 1.5, which indicates the presence of positive autocorrelation.

According to forecasting results evaluations, we found that the Norton-Bass model is accurate for the problem treated in this paper.

\section{CONCLUSION}

As a product of NFC technology implementation in m-commerce business models, a need arises for expanding the B2B2C business model towards service integration with the aim of creating new products and markets and tuning to user needs, particularly on local markets such as Serbia. Development of new 
communication services/products requires many years of efforts and considerable financial investments, and in that process it is necessary to pay attention to the relevance of forecasting the market reaction in regard to a new offered service. This paper presents a new approach for evaluation of the NFC technology imitation parameter by applying fuzzy logic. The obtained results have shown that $84 \%$ of the total number of mobile phone users in Serbia is ready to transit from NFC contactless cards to NFC mobile phones as a platform for the development of NFC technology business services in Serbia. The high percentage of users that approve this platform introduces the possibility for all new NFC business services to be developed on the NFC mobile platform, while pointing to the need for such services from the aspect of economy and efficiency development.

Diffusion models have been used traditionally in marketing for predicting new product/technology lifecycle dynamics, demand forecasting, and marketing strategy decision-making. This paper uses many aspects of demand forecasting. Some relate to judg ment, such as Delphi, expert opinions surveys, and fuzzy logic, and others relate to quantitative methods such as the diffusion model. The main advantage of this paper is that it provides an integration of statistical and judgmental forecasts. We presented the obtained results of the forecasted number of NFC mobile phone users on the Serbian market. For the validation of the considered forecasting model we used standard statistical error measures (MAE and MAPE) as well as the Durbin-Watson test.

Such forecasting is not only important for providers introducing innovative technologies, but also for all others that provide related complementary technologies. The evaluated NFC technology innovation and imitation parameters for the Serbian market provides a good basis for the diffusion model application with the aim of providing long-term forecasts for acceptance of new technologies in the market.

\section{ACKNOWLEDGMENT}

This research was supported by Serbian Ministry of Education, Science and Technological Development with projects TR36022 and TR32025.

\section{Doc. dr BOJAN STANIVUKOVIĆ ${ }^{1}$}

E-mail: stanivukovic@yahoo.com

Prof. dr VALENTINA RADOJIČIĆ ${ }^{1}$

E-mail: valentin@sf.bg.ac.rs

Prof. dr DEJAN MARKOVIĆ ${ }^{1}$

E-mail: mdejan@sf.bg.ac.rs

Doc. dr MLADENKA BLAGOJEVIĆ ${ }^{1}$

E-mail: m.blagojevic@sf.bg.ac.rs

1 Univerzitet u Beogradu, Saobraćajni fakultet

Vojvode Stepe 305, 11000 Beograd, Srbija

\section{PREDVIĐANJE BROJA KORISNIKA NFC MOBILNIH TELEFONA - STUDIJA SLUČAJA TRŽIŠTA SRBIJE}

\section{SAŽETAK}

NFC (Near Field Communication) je radio komunikacija vrlo kratkog dometa koja je kompatibilna sa ostalim beskontaktnim komunikacionim tehnologijama, sa izuzetno velikim mogućnostima, posebno imajući u vidu da ne zahteva posebnu komunikacionu infrastrukturu. Moguću primenu ova tehnologija našla je u beskontaktnim karticama i mobilnim telefonskim uređajima kao novoj platformi za razvoj poslovnih usluga. Ovaj rad predlaže nov pristup za predviđanje broja novih korisnika NFC mobilnih telefona, zasnovan na fazi logici i Norton-Bass difuzionom modelu. Predloženi pristup je prikazan kroz studiju slučaja.

\section{KLUČNE REČI}

fazi logika; NFC; mobilni korisnici; prognoza;

\section{REFERENCES}

[1] Pal D, Vanijja V, Papasratorn B. An Empirical Analysis towards the Adoption of NFC Mobile Payment System by the End User. Procedia Computer Science. 2015;69: 13-25.

[2] Slade EL, Williams MD, Dwivedi YK. Extending UTAUT2 to explore consumer adoption of mobile payments. In: Proceedings of the UK Academy for Information Systems Conference, Oxford; 2013.

[3] Amoroso DL, Magnier-Watanabe R. Building a research model for mobile wallet consumer adoption: the case of Mobile Suica in Japan. J. Theor. Appl. Electron. Commer. Res. 2012;7(1): 94-110.

[4] Dahlberg T, Guo J, Ondrus J. A critical review of mobile payment research. Electronic Commerce Research and Applications. 2015;14(5): 265-284.

[5] Oliveira T, Thomas M, Baptista G, Campos F. Mobile payment: Understanding the determinants of customer adoption and intention to recommend the technology. Computers in Human Behavior. 2016;61: 404-414.

[6] Ooi K-B, Tan GW-H. Mobile technology acceptance model: An investigation using mobile users to explore smartphone credit card. Expert Systems with Applications. 2016;59: 33-46.

[7] Leong L, Hew T, Tan GW-H, Ooi K-B. Predicting the determinants of the NFC-enabled mobile credit card acceptance: A neural networks approach. Expert Systems with Applications. 2013;40(14): 5604-5620.

[8] Pham TT, Ho J. The effects of product-related, personal-related factors and attractiveness of alternatives on consumer adoption of NFC-based mobile payments. Technology in Society. 2015;43: 159-172.

[9] RATEL. An Overview of the Telecom and Postal Services Market in the Republic of Serbia in 2015. Available from: http://www.ratel.rs/regulativa/analize_trzista.539.html

[10] Ecma International. Standard ECMA-352, Near Field Communication Interface and Protocol-2-2. Geneve: 2010. Available from: http://www.ecmainternational. org/publications/files/ECMA-ST/Ecma-352.pdf

[11] Madlmayr G, Langer J, Scharinger J. Managing an NFC 
Ecosystem. In: Proceedings of $7^{\text {th }}$ International Conference on Mobile Business 2008 (ICMB 2008), Barcelona; 2008. p. 95-101.

[12] The Java Community Process. Available from: http:// www.jcp.org /en/jsr/detail?id=257 (Accessed 09 November 2015)

[13] Rukzio E, Schmidt A, Hussmann H. Physical Posters as Gateways to Context-aware Services for Mobile Devices. In: Proceedings of Sixth IEEE Workshop on Mobile Computing Systems and Applications (WMCSA 2004). English Lake District, UK. IEEE; 2004. p. 10-19.

[14] Dahlberg T, Mallat N, Ondrus J, Zmijewska A. Past, present and future of mobile payments research: A literature review. Electronic Commerce Research and Applications. 2008;7(2): 165-181.

[15] Madureira A. Factors that hinder the success of SIMbased mobile NFC service deployments. Telematics and Informatics. 2017;34(1): 133-150.

[16] [16] Tagawa K. NFC: The Evolution Continues. NFC Forum, WIMA Monaco. Paper Presented at the $5^{\text {th }} \mathrm{Global}$ NFC Applications Products \& Service Congress, Monaco; 2011.

[17] NFC Forum. Available from: http://www.NFC forum.org (Accessed 06 November 2015)

[18] Hassinen M. Utilizing national public-key infrastructure in mobile payment systems. Electronic Commerce Research and Applications. 2008;7(2): 214-231.

[19] NXP Semiconductors. Available from: http://www.nxp. com/ (Accessed 28 October 2015)

[20] Chidembo N. Exploring consumer adoption of NFC-enabled mobile payments in South Africa. Master thesis. University of Pretoria, South Africa; 2009.

[21] Madlmayr G, Langer J, Kantner C, Scharinger J. NFC devices: Security and privacy. In: Proceedings of the third international conference on availability, reliability and security, Barcelona; 2008. p. 642-647.

[22] Zadeh LA. Fuzzy sets. Information and Control. 1965;8: 338-353.

[23] Mamdani EH. Advances in the linguistic synthesis of fuzzy controllers. In: Mamdani EH, Gaines BR. (Eds.) Fuzzy Reasoning and its Applications. London, UK: Academic Press; 1981.

[24] Mamdani EH, Assilian S. Experiment in linguistic synthesis with a fuzzy logic controller. International Journal of Man-Machine Studies. 1975;7: 1-13.

[25] Tettamanzi A, Carlesi M, Pannese L, Santalmasi M. Business Intelligence for Strategic Marketing: Predictive Modelling of Customer Behaviour Using Fuzzy Logic and Evolutionary Algorithms. In: Giacobini M, et al. (Eds.) Applications of Evolutionary Computing. Springer-Verlag Berlin Heidelberg; 2007. p. 233-240.

[26] Escoda A, Ortega A, Sanz A, Herms A. Demand forecast by neuro-fuzzy techniques. In: Proceedings of the Sixth IEEE International Conference, Barcelona. IEEE; 1997. p. 1381-1386.

[27] Guiffrida I, Nagi R. Fuzzy set theory applications in production management research: A literature survey. Journal of Intelligent Manufacturing. 1998;9: 39-56.

[28] Radojičić V, Marković G, Bakmaz B. New Diffusion
Model with Variable Market Potential. In: Proceedings of $10^{\text {th }}$ International Conference on Telecommunications in Modern Satellite, Cable and Broadcasting Services (TELSIKS), Niš, Serbia. IEEE; 2011. p. 637-640.

[29] Bass F. A New Product Growth Model for Consumer Durables. Management Science. 1969;15(1): 215-227.

[30] Mahajan V, Peterson R. Models for Innovation Diffusion. Newbury Park, CA: Sage; 1985.

[31] Meade N, Islam T. Modelling and forecasting the diffusion innovation - A 25-year review. International Journal of Forecasting. 2006;22(3): 519-545.

[32] Kim N, Chang DR, Shocker AD. Modelling intercategory and generational dynamic for a growing information technology industry. Management Science. 2000;46(4): 496-512.

[33] Mahajan V, Muller E. Timing, diffusion, and substitution of successive generations of technological innovations: The IBM mainframe case. Technological Forecasting and Social Change. 1996;51(2): 109-132.

[34] Norton JA, Bass FM. Evolution of Technological Generations: The Law of Capture. Sloan Management Review. 1992;33: 66-77.

[35] Pae JH, Lehmann DR. Multigeneration innovation diffusion: The impact of intergeneration time. Journal of the Academy of Marketing Science. 2003;31(1): 36-45.

[36] Dereli T, Durmusoglu A, Daim T. Buyer/seller collaboration through measurement of beliefs on innovativeness of products. Computers in Industry. 2011;62: 205-212.

[37] Norton JA, Bass FM. A Diffusion Theory Model of Adoption and Substitution for Successive Generations of High Technology Product. Management Science. 1987;33: 1069-1086.

[38] Teodorović D, Šelmić M. Computer Intelligence in Traffic. [in Serbian]. Belgrade: Faculty of Transport and Traffic Engineering; 2012.

[39] Green K, Armstrong S, Graefe A. Methods to Elicit Forecasts from Groups: Delphi and Prediction Markets Compared. The International Journal of Applied Forecasting. 2007;8: 17-20.

[40] Radojičić V, Marković G, Janković M, Drašković B. Broadband Traffic Forecasting in the Transport Network. Promet - Traffic \& Transportation. 2012;24(4): 275-284.

[41] Radojičić V, Bakmaz B. The application of quantitative methods of forecasting in telecommunications [in Serbian]. Belgrade: Faculty of Transport and Traffic Engineering; 2010.

[42] Satoh DA. Discrete Bass Model and its Parameter Estimation. Journal of the Operations Research. Society of Japan. 2001;44(1): 1-18.

[43] Hamilton JD. Time Series Analysis. Vol. 2. Princeton: Princeton University Press; 1994.

[44] Lewis CD. International and Business Forecasting Methods. London: Butterworths; 1982.

[45] Montgomery DC, Peck EA, Vining GG. Introduction to Linear Regression Analysis. $3^{\text {rd }}$ ed. New York: John Wiley \& Sons; 2001. 